\title{
Mechanism of Electron and Hole Localization \\ in Poly(dimethylsilane) radical ions
}

\author{
Hiroto TACHIKAWA* \\ Department of Materials Chemistry, Graduate School of Engineering, Hokkaido University, \\ Sapporo 060-8628, Japan
}

1. Spin density distributions calculated by means of EHMO, ROHF and MP2 methods
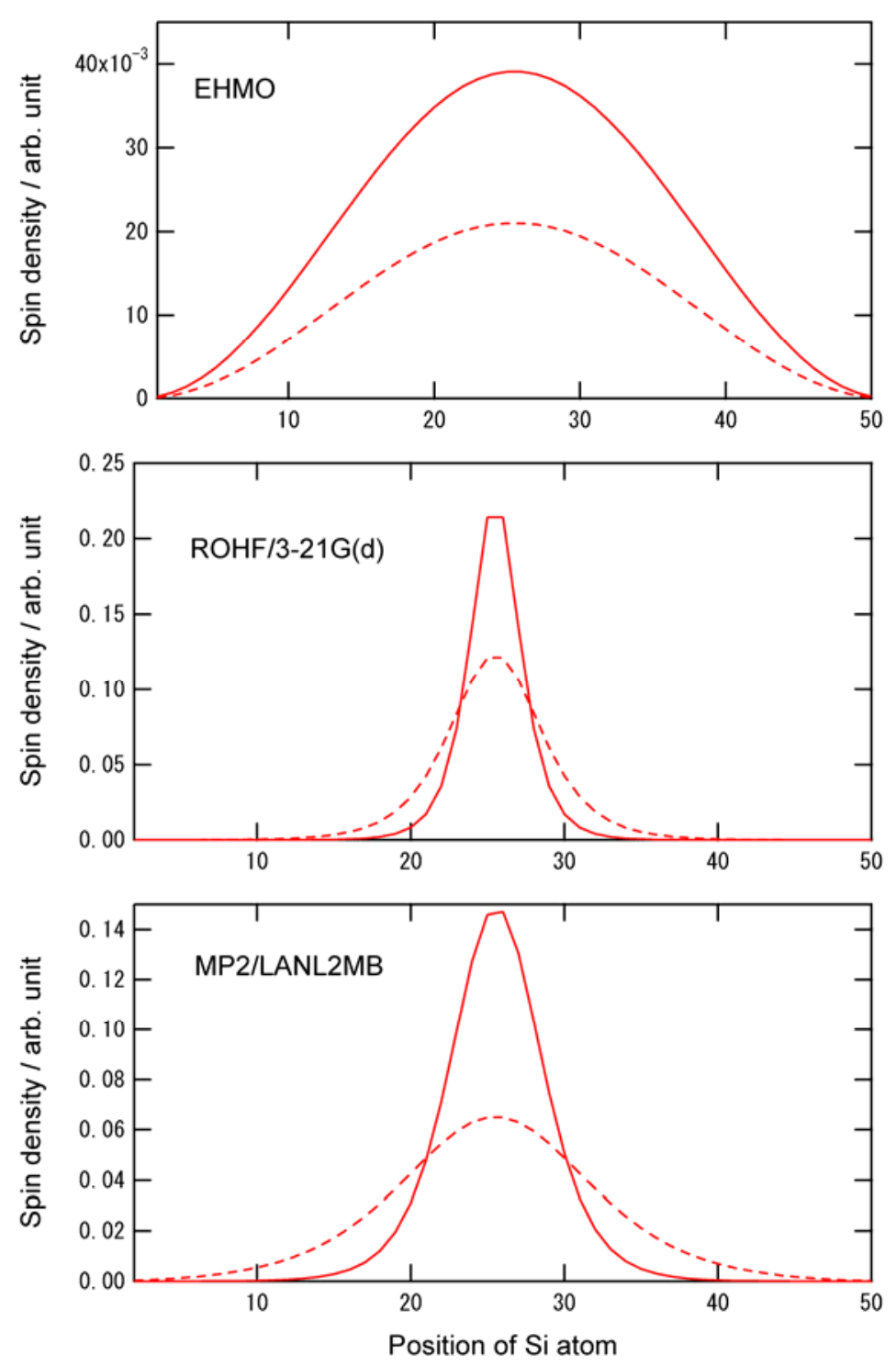

Figure S1. Spin densities of the hole and excess electron in $\mathrm{CH}_{3}\left(\mathrm{Si}\left(\mathrm{CH}_{3}\right)_{2}\right)_{n} \mathrm{CH}_{3}(\mathrm{n}=50)$ calculated by means of extended Huckel $\mathrm{MO}$ (EHMO), ROHF/3-21G(d) and MP2/LANL2MB methods. Solid and dashed lines indicate spin densities of cation and anion radicals, respectively. 
2. Spin density distributions calculated by means of DFT (B3LYP and PW91PW91) methods

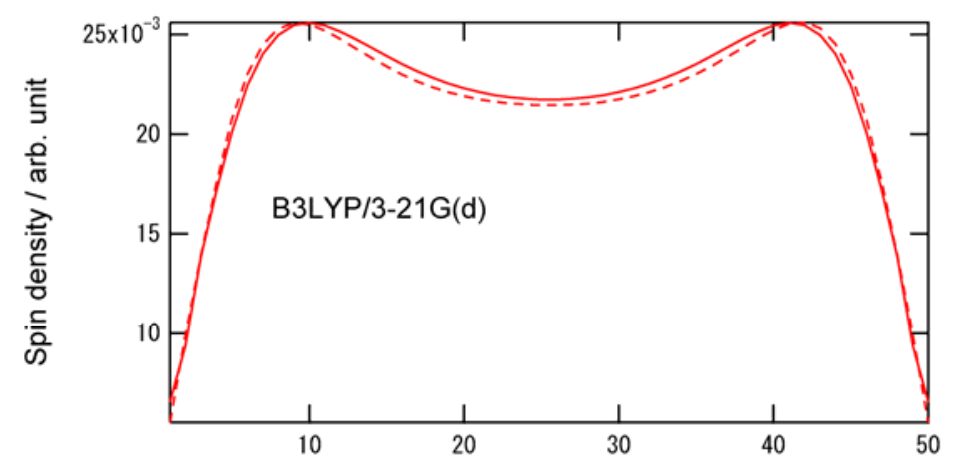

Figure S2. Spin densities of the hole and excess electron in $\mathrm{CH}_{3}\left(\mathrm{Si}\left(\mathrm{CH}_{3}\right)_{2}\right)_{n} \mathrm{CH}_{3}(\mathrm{n}=50)$ calculated by means of B3LYP and PW91 methods. Solid and dashed lines indicate spin densities of cation and anion radicals, respectively.

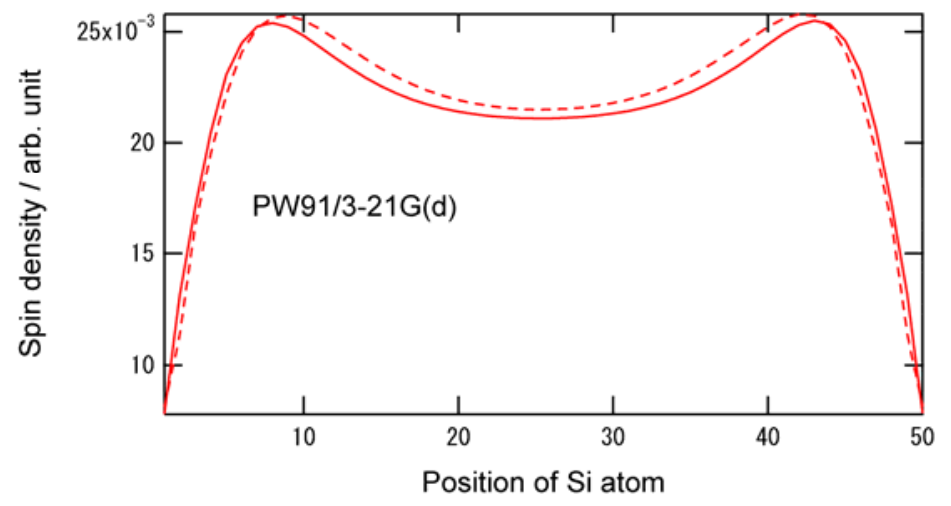

